\title{
PENGARUH KONFLIK DAN STRES KERJA TERHADAP KINERJA TENAGA KESEHATAN DI RSUD WANGAYA DENPASAR
}

\section{THE EFFECT OF CONFLICT AND WORK STRESS ON THE PERFORMANCE OF HEALTH WORKERS IN WANGAYA GENERAL HOSPITAL}

\author{
Zainal Firdaus Wardhana ${ }^{1}$, Theresia Anita Pramesti ${ }^{2}$, Ni Luh Gede Aris Maytadewi ${ }^{3}$, Ni \\ Putu Liana Indah Savitri ${ }^{4}$ \\ ${ }^{1,4}$ Program Studi Administrasi Rumah Sakit, Fakultas Ilmu-Ilmu Kesehatan, Universitas Bali \\ Internasional \\ ${ }^{2}$ STIKes Wira Medika Bali \\ ${ }^{3}$ Program Studi Kesehatan dan Keselamatan Kerja, Fakultas Ilmu-Ilmu Kesehatan, Universitas \\ Bali Internasional
}

\begin{abstract}
ABSTRAK
Sumber daya manusia merupakan salah satu faktor yang menentukan kesuksesan organisasi dan menjadi pemeran utama setiap kegiatan agar tujuan organisasi yang akan diraih dapat tercapai diperlukan kinerja dari para pegawainya. Adapun faktor yang mempengaruhi kinerja tenaga kesehatan, salah satunya yaitu konflik dan stres kerja. Penelitian ini bertujuan untuk mengetahui pengaruh konflik dan stres kerja terhadap kinerja tenaga kesehatan di RSUD Wangaya Denpasar. Penelitian ini merupakan penelitian kuantitatif dengan rancangan penelitian explanatori (explanatory research). Alat ukur atau instrumen dalam penelitian ini adalah angket/kuesioner. Konflik dan Stres Kerja berpengaruh negatif dan signifikan terhadap Kinerja Tenaga Kesehatan di RSUD Wangaya Denpasar yaitu sebesar 47,5\% dengan nilai $t$ hitung $(4,521$ dan 5,101) $>\mathrm{t}$ tabel $(2,000)$ dengan tingkat konflik sedang sebesar 74,4\%; tingkat stres kerja sedang sebesar 91,9\%; dan tingkat kinerja sedang sebesar 55,8\%. Konflik dan Stres Kerja berpengaruh negatif dan signifikan terhadap Kinerja Tenaga Kesehatan di RSUD Wangaya Denpasar, sehingga manajemen SDM di RSUD Wangaya Denpasar.
\end{abstract}

Kata Kunci: kinerja tenaga kesehatan, konflik, stres kerja

\section{ABSTRACT}

Human resources are one of the factors that determine the success of an organization and become the main actor in every activity so that the organization's objectives to be achieved can be needed by the performance of its employees. The factors that affect the performance of health workers, one of which is conflict and work stress. This study aims to determine the effect of conflict and work stress on the performance of health workers in Wangaya General Hospital. This research is 
Bali Medika Jurnal.

Vol 8 No 1, 2021: 13-26

ISSN : 2615-7047

DOI: https://doi.org/10.36376/bmj.v8i1

a quantitative study with an explanatory research. The measuring instrument in this study was a questionnaire. Conflict and Work Stress has a negative and significant effect on the Performance of Health Workers in Wangaya General Hospital that is equal to $47,5 \%$ with $t$ test $(4,521$ and 5,101$)>t$ table $(2,000)$ with a moderate conflict level of $74,4 \%$; moderate work stress level of $91,9 \%$ and moderate performance level of 55,8\%. Conflict and Work Stress has a negative and significant effect on the Performance of Health Workers in Wangaya General Hospital.

Keywords: conflict, performance of health workers, work stress

\begin{tabular}{ll}
\hline Alamat Korespondensi & $:$ Fakultas Ilmu-Ilmu Kesehatan, Universitas Bali \\
& Internasional \\
Email & : pinnoo.pinnii@gmail.com \\
\hline
\end{tabular}

\section{PENDAHULUAN}

Sumber daya manusia merupakan salah satu faktor yang menentukan kesuksesan organisasi dan menjadi pemeran utama setiap kegiatan agar tujuan organisasi yang akan diraih dapat tercapai diperlukan kinerja dari para pegawainya. Adapun faktor yang mempengaruhi kinerja pegawai, salah satunya yaitu konflik dan stres kerja. Data dari International Labor Organization (ILO) tahun 2013 menjelaskan bahwa tenaga kerja dunia terdiri dari 484,7 juta pegawai dengan persentase sebesar $49,9 \%$ dari total populasi 974 juta jiwa di dunia dengan $8 \%$ diantaranya penyakit yang ditimbulkan akibat kerja adalah stres (World Health Organization, 2015). Hasil data Labour Force Survey tahun 2017 menemukan 595.000 kasus stres kerja dialami oleh pegawai di Inggris (Health and Safety Executive, 2018).

Stres kerja yang sering terjadi dan dirasakan bertahun-tahun menyebabkan seseorang mengalami stres kerja kronis. Data dari American Psychological Association (APA) tahun 2018 menyatakan lebih dari sepertiga orang Amerika yang bekerja dengan persentase sebesar 35\% melaporkan mengalami stres kerja kronis. Hasil yang diungkapkan oleh Accountemps (Lembaga Penyedia Tenaga Kerja di Amerika Serikat) tahun 2016 setelah meneliti 1000 pegawai di Amerika Serikat menjelaskan sebesar $60 \%$ partisipan setuju bahwa stres akibat pekerjaan telah meningkat drastis selama lima tahun terakhir. Hasil penelitian di Asia yang dilakukan oleh Labor Force Survey (LFS) dipublikasi di Philippine Statistics Authority (2016), yaitu sebesar 56\% tenaga kerja mengalami masalah stres.

Stres kerja merupakan gangguan psikologis yang dialami oleh pegawai. Gangguan psikologis ini sering dialami oleh para pegawai, seperti: merasa cemas, tengang, mudah marah, menurunnya rasa percaya diri, dan ketidakpuasan kerja (Waluyo, 2013). Jika melihat pegawai yang bekerja di Rumah Sakit Akademiska di Swedia dapat dijelaskan bahwa dokter dan bidan mengalami stres kerja sebesar $15 \%$ (Wahlberg et al., 2016), sedangkan dokter di rumah sakit China mengalami ketidakpuasan kerja karena stres kerja sebesar 95\% (Cui, Dunning, \& An, 2017). Survei dari Cigna (perusahaan penyedia solusi keuangan yang bergerak di bidang asuransi kesehatan) tahun 2018 mengatakan bahwa penduduk Indonesia merasa 
Bali Medika Jurnal.

Vol 8 No 1, 2021: 13-26

ISSN : 2615-7047

DOI: https://doi.org/10.36376/bmj.v8i1

stres kerja sebesar 75\%. Hasil penelitian Yana (2014) dilakukan di RSUD Pasar Rebo Jakarta menunjukkan bahwa sebanyak $46,2 \%$ tenaga kesehatan yaitu perawat mengalami stres kerja yang tinggi. Tingkat stres kerja tenaga kesehatan yaitu perawat di Rumah Sakit Umum Pusat (RSUP) Sanglah Provinsi Bali menunjukkan bahwa perawat mengalami stres kerja dengan kategori sedang sebesar $61,88 \%$. Adapun faktor yang mempengaruhi stres kerja di RSUP Sanglah yaitu beban kerja, lingkungan kerja dan aktivitas di luar pekerjaan (Putra \& Susilawati, 2018).

Hal lain dari stres kerja yaitu konflik juga dialami oleh pegawai dan menjadi faktor yang berpengaruh terhadap kinerja. Keberadaan konflik dalam organisasi tidak dapat dihindarkan dan selalu hadir dalam suatu organisasi. Survey dari Majority of Employees Experience Conflict at Work oleh perusahaan rekrutmen Find Employment England (2014), sebesar 74\% pegawai melaporkan mengalami konflik selama karir mereka, dan responden lain sebesar 43\% menilai konflik yang terjadi adalah konflik kecil. Hasil penelitian Yana (2014) dilakukan di RSUD Pasar Rebo Jakarta menunjukkan bahwa sebesar $60 \%$ tenaga kesehatan yaitu perawat mengalami konflik kerja yang tinggi. Psychometrics Canada (Lembaga Survey di Kanada) tahun 2015 yang telah melakukan penelitian melibatkan 357 orang profesional di bidang sumber daya manusia sebagai responden. Sebesar $87 \%$ responden melihat adanya manfaat yang dihasilkan oleh konflik di tempat kerja mereka. Menurut hasil survey tersebut, manfaat yang diperoleh dari konflik adalah: (1) setiap orang jadi dapat memahami orang lain lebih baik sebesar 77\%, (2) bisa menghasilkan solusi yang lebih baik ketika menghadapi masalah dan tantangan sebesar 57\%, (3) memperbaiki hubungan kerja sebesar 54\%, (4) kinerja tim jadi lebih tinggi sebesar 40\%, (5) dapat meningkatkan motivasi sebesar 31\%, (6) lahirnya inovasi besar atau ide baru di tempat kerja sebesar $21 \%$.

Dewasa ini para manajer mempunyai dua sudut pandang dalam menangani konflik yaitu pandangan tradisional dan pandangan kontemporer. Pandangan tradisional adalah konflik dapat menghambat tujuan organisasi sehingga konflik ditiadakan dan dihindari sedangkan pandangan kontemporer yaitu konflik tidak dihindarkan karena konflik membuat kinerja menjadi optimal, dapat membuat perubahan, anggota dapat bertoleransi terhadap kesalahan sehingga masalah terselesaikan (Sinambela, 2017). Hal ini menuai hal yang kontradiktif dan patut dikaji untuk memberikan rekomendasi yang tepat bagi organisasi/industri (perusahaan).

Pelayanan di rumah sakit tentunya memiliki sumber daya manusia dengan berbagai macam pendidikan dari jenjang terendah sampai spesialis, serta pegawai rumah sakit melayani masyarakat sehat maupun sakit dalam 24 jam (Khamisa, Peltzer, Ilic, \& Oldenburg, 2017). Ada berbagai hasil penelitian terkait pengaruh konflik dan stres kerja terhadap kinerja pegawai. Hasil penelitian Andri (2016) menyatakan bahwa konflik dan stres kerja berpengaruh positif signifikan terhadap kinerja pegawai di RSUP Dr. Cipto Mangunkusumo, hasil tersebut sejalan dengan Setiawan (2017) menyatakan bahwa konflik berpengaruh positif signifikan terhadap kinerja di Rumah Sakit Undata Palu dan juga Januar (2018) menyatakan bahwa stres berpengaruh positif signifikan terhadap kinerja pegawai di Rumah Sakit Daerah Kalisat.

Hasil studi pendahuluan yang sudah peneliti lakukan di RSUD Wangaya Denpasar menyatakan bahwa jumlah tenaga kesehatan adalah sebanyak 595 orang 
Bali Medika Jurnal.

Vol 8 No 1, 2021: 13-26

DOI: https://doi.org/10.36376/bmj.v8i1

pada tahun 2017. Jumlah tenaga kesehatan tersebut mengalami penurunan tahun 2019 menjadi sebanyak 586 orang. Jumlah tenaga kesehatan tersebut 50,5\% adalah tenaga keperawatan (Data pegawai RSUD Wangaya Denpasar tahun 2019). Perawat merupakan salah satu komponen penting dalam memberikan pelayanan kesehatan di rumah sakit. Perawat mempunyai intensitas interaksi paling tinggi dengan pasien dan keluarga dalam memberikan pelayanan kesehatan. Begitu pula dengan dokter, bidan dan tenaga kesehatan lainnya. Kinerja tenaga kesehatan kini terus menjadi perhatian berbagai pihak. Kinerja seorang tenaga kesehatan dapat dilihat dari mutu asuhan tenaga kesehatan yang diberikan kepada pasien. Maka dari itu, kinerja pelayanan tenaga kesehatan merupakan indikator baik buruknya kualitas pelayanan yang ada di rumah sakit (Pratika, 2017).

Hasil dari wawancara yang sudah dilakukan pada tenaga kesehatan di RSUD Wangaya Denpasar didapatkan beberapa perawat pernah mengalami konflik berupa perbedaan pendapat dengan rekan kerjanya, namun tidak sampai terjadi percekcokkan yang lama. Perawat juga pernah merasakan stres kerja disebabkan oleh lingkungan kerja, perbedaan karakter dan beban kerja. Beban kerja dikarenakan kurangnya tenaga perawat yang saat ini masih dibutuhkan sebanyak 32 orang lagi. Begitu pula dengan dokter masih dibutuhkan sebanyak 13 orang dan bidan masih dibutuhkan sebanyak 28 orang (Data pegawai RSUD Wangaya Denpasar Tahun 2019).

Berdasarkan uraian yang telah disampaikan, terlihat terjadinya fenomena permasalahan antara konflik dan stres kerja terhadap kinerja tenaga kesehatan, terdapat research gap dari penelitian-penelitian sebelumnya, dan juga belum banyaknya penelitian yang serupa dilakukan di RSUD Wangaya Denpasar sehingga hal tersebut yang melatarbelakangi peneliti untuk melakukan penelitian tentang pengaruh konflik dan stres kerja terhadap kinerja tenaga kesehatan di RSUD Wangaya Denpasar.

\section{METODE PENELITIAN}

Penelitian ini merupakan penelitian kuantitatif dengan rancangan penelitian explanatori (explanatory research), menggunakan pendekatan cross sectional. Penelitian ini telah dilaksanakan di RSUD Wangaya Denpasar dan dilakukan pada tanggal 5 Agustus 2019 sampai dengan 9 Agustus 2019. Populasi dalam penelitian ini adalah tenaga kesehatan di RSUD Wangaya Denpasar dengan jumlah populasi sebanyak 586 orang dengan jumlah sampel yang digunakan sebanyak 86 responden, sesuai kriteria inklusi dan eksklusi. Adapun kriteria inklusi yang digunakan antara lain: Tenaga kesehatan yang masih aktif bekerja, Lama kerja $\geq 6$ bulan, Usia $\geq 21$ tahun, sedangkan kriteria eksklusi yang digunakan antara lain: tenaga kesehatan yang tidak bersedia mengisi kuesionair dan tenaga kesehatan yang saat penelitian menderita sakit. Teknik sampling yang digunakan dalam penelitian ini adalah non probability sampling yaitu dengan proportionate sampling. Data dikumpulkan menggunakan kuesioner yang sudah diuji validitas dan reabilitasnya. Hasil tingkat konflik, stress kerja, dan kinerja didapatkan dari jumlah jawaban dari pernyataan negatif (unfavorable) responden dibagi total nilai konflik seluruhnya dikali 100\%, dengan kategori untuk konflik dan stress kerja adalah Tinggi (0-55\%), Sedang (5675\%), dan Rendah (76-100\%), sedangkan untuk kinerjan dikategorikan menjadi 
Tinggi (76-100\%), Sedang (56-75\%), dan Rendah (0-55\%). Analisis data yang dipergunakan adalah teknik analisis regresi linier berganda.

\section{HASIL DAN PEMBAHASAN}

\section{Hasil penelitian}

Tabel 1

Karakteristik Responden

\begin{tabular}{|c|c|c|c|}
\hline No & Karakteristik & Frekuensi & $(\%)$ \\
\hline \multirow[t]{8}{*}{1} & Umur & & \\
\hline & 20-24 tahun & 11 & 12,8 \\
\hline & 25-29 tahun & 25 & 29,1 \\
\hline & 30-34 tahun & 21 & 24,4 \\
\hline & 35-39 tahun & 17 & 19,8 \\
\hline & 40-44 tahun & 7 & 8,1 \\
\hline & 45-49 tahun & 4 & 4,7 \\
\hline & 50-54 tahun & 1 & 1,2 \\
\hline \multirow[t]{3}{*}{2} & Jenis Kelamin & & \\
\hline & Laki-Laki & 25 & 29,1 \\
\hline & Perempuan & 61 & 70,9 \\
\hline \multirow[t]{3}{*}{3} & Status Perkawinan & & \\
\hline & Sudah Menikah & 57 & 66,3 \\
\hline & Belum Menikah & 29 & 33,7 \\
\hline \multirow[t]{4}{*}{4} & Pendidikan & & \\
\hline & D3 & 48 & 55,8 \\
\hline & $\mathrm{D} 4 / \mathrm{S} 1$ & 33 & 38,4 \\
\hline & $\mathrm{S} 2$ & 5 & 5,8 \\
\hline \multirow[t]{6}{*}{5} & Lama Bekerja & & \\
\hline & $0-4$ tahun & 24 & 27,9 \\
\hline & 4-8 tahun & 26 & 30,2 \\
\hline & 8-12 tahun & 19 & 22,1 \\
\hline & 12-16 tahun & 15 & 17,4 \\
\hline & 16-20 tahun & 2 & 2,3 \\
\hline \multirow[t]{10}{*}{6} & Profesi & & \\
\hline & Dokter & 15 & 17,4 \\
\hline & Farmasi & 5 & 5,8 \\
\hline & Perawat & 42 & 48,8 \\
\hline & Bidan & 13 & 15,1 \\
\hline & Kesehatan Masyarakat & 2 & 2,3 \\
\hline & Gizi & 3 & 3,5 \\
\hline & Keterapian Fisik & 1 & 1,2 \\
\hline & Keteknisan Medis & 5 & 5,8 \\
\hline & Jumlah & 86 & 100 \\
\hline
\end{tabular}


Berdasarkan hasil karakteristik tersebut didapatkan hasil karakteristik didominasi oleh responden berumur 25-29 tahun yaitu 25 orang (29,1\%), sebagian besar berjenis kelamin perempuan sebanyak 61 orang $(70,9 \%)$, sebagian besar responden sudah menikah sebanyak 57 orang $(66,3 \%)$, sebagian besar berpendidikan D3 sebanyak 48 orang $(55,8 \%)$, didomonasi oleh responden dengan lama bekerja 4-8 tahun sebanyak 26 orang (30,2\%), dan didominasi yang berprofesi sebagai perawat sebanyak 42 orang $(48,8 \%)$.

Tabel 2

Gambaran Tingkat Konflik

\begin{tabular}{clccc}
\hline No & Tingkat Konflik & Nilai Jawaban & Frekuensi & $(\mathbf{\%})$ \\
\hline 1 & Tinggi & $0-55 \%$ & 0 & 0 \\
2 & Sedang & $56-75 \%$ & 64 & 74,4 \\
3 & Rendah & $76-100 \%$ & 22 & 25,6 \\
\hline & & Jumlah & 86 & 100 \\
\hline
\end{tabular}

Berdasarkan hasil tersebut didapatkan bahwa tingkat konflik yang terjadi pada tenaga kesehatan di RSUD Wangaya Denpasar sebagian besar mengalami konflik sedang yaitu sebesar $74,4 \%$.

Tabel 3

Gambaran Tingkat Stres Kerja

\begin{tabular}{rlccc}
\hline No & Tingkat Stres Kerja & Nilai Jawaban & Frekuensi & $\mathbf{( \% )}$ \\
\hline 1 & Tinggi & $0-55 \%$ & 0 & 0 \\
2 & Sedang & $56-75 \%$ & 79 & 91,9 \\
3 & Rendah & $76-100 \%$ & 7 & 8,1 \\
\hline & & Jumlah & 86 & 100 \\
\hline
\end{tabular}

Berdasarkan hasil tersebut didapatkan bahwa tingkat konflik yang terjadi pada tenaga kesehatan di RSUD Wangaya Denpasar sebagian besar merasakan stres kerja sedang yaitu sebesar 91,9\%.

Tabel 4

Gambaran Tingkat Kinerja Tenaga Kesehatan

\begin{tabular}{rlccc}
\hline No & Tingkat Kinerja & Nilai Jawaban & Frekuensi & (\%) \\
\hline 1 & Tinggi & $76-100 \%$ & 38 & 44,2 \\
2 & Sedang & $56-75 \%$ & 48 & 55,8 \\
3 & Rendah & $0-55 \%$ & 0 & 0 \\
\hline & & Jumlah & 86 & 100 \\
\hline
\end{tabular}

Berdasarkan hasil tersebut didapatkan bahwa tingkat kinerja tenaga kesehatan yang terjadi pada tenaga kesehatan di RSUD Wangaya Denpasar sebagian besar memiliki kinerja sedang yaitu sebesar 55,8\%.

Tabel 5

Hasil Uji Normalitas

\begin{tabular}{lcc}
\hline Uji Kolmogorov-Smirnov Z & Unstandardized Residual & Kesimpulan \\
\hline Asymp. Sig. (2-tailed) & 0,951 & Normal
\end{tabular}


Berdasarkan hasil uji normalitas tersebut menunjukkan bahwa nilai probabilitas (signifikansi) yaitu 0,951 dengan tingkat signifikansi berada di atas 0,05 dengan demikian dapat disimpulkan bahwa variabel telah terdistribusi secara normal.

Tabel 6

Hasil Uji Multikolinearitas

\begin{tabular}{lccl}
\hline Variabel & Tolerance & \multicolumn{1}{l}{ VIF } & Kesimpulan \\
\hline Konflik & 0,829 & 1,206 & Tidak terjadi multikolinearitas \\
\hline Stres Kerja & 0,829 & 1,206 & Tidak terjadi multikolinearitas \\
\hline
\end{tabular}

Berdasarkan hasil uji normalitas tersebut menunjukkan bahwa nilai probabilitas (signifikansi) yaitu 0,951 dengan tingkat signifikansi berada di atas 0,05 dengan demikian dapat disimpulkan bahwa variabel telah terdistribusi secara normal.

Tabel 7

Hasil Uji Heteroskedastisitas

\begin{tabular}{lcl}
\hline Variabel & Signifikan & Kesimpulan \\
\hline Konflik & 0,701 & Tidak terjadi heterokedastisitas \\
\hline Stres Kerja & 0,435 & Tidak terjadi heterokedastisitas \\
\hline
\end{tabular}

Hasil pengujian menunjukkan bahwa semua variabel menunjukkan nilai signifikan $>0,05$. Hal ini berarti bahwa variabel-variabel penelitian tidak menunjukkan adanya gejala heterokedastisitas dalam model regresi. Maka dari itu, kedua variabel bebas dapat digunakan sebagai variabel independen sebagai prediktor yang tidak bias.

Tabel 8

Hasil Uji Koefisien Determinasi $\left(\mathrm{R}^{2}\right)$

\begin{tabular}{ll}
\hline R square & Adjusted R Square \\
\hline 0,488 & 0,475 \\
\hline
\end{tabular}

Berdasarkan hasil uji $\mathrm{R}^{2}$, diperoleh nilai Adjusted $\mathrm{R}^{2}$ sebesar 0,475 atau 47,5\%. Hal ini menunjukkan bahwa kinerja tenaga kesehatan dapat dijelaskan sebesar $47,5 \%$ oleh variabel independen yaitu konflik dan stres kerja, sedangkan $52,5 \%$ kinerja tenaga kesehatan dijelaskan oleh variabel-variabel diluar variabel independen penelitian ini.

Tabel 9

\begin{tabular}{ll}
\multicolumn{2}{c}{ Hasil Uji Kelayakan Model (Uji F) } \\
\hline Uji & Nilai \\
\hline F hitung & 39,515 \\
\hline Sig. F & 0.000 \\
\hline
\end{tabular}

Berdasarkan hasil uji kelayakan (Uji F) tersebut dapat dilihat bahwa model persamaan ini memiliki nilai $\mathrm{F}$ hitung sebesar 39,515 dengan tingkat signifikansi 0,000 . Nilai signifikansi sebesar 0,000 lebih kecil dari alpha 0,05 maka menunjukan bahwa kinerja dapat dijelaskan oleh konflik dan stres kerja. Maka dari itu dapat disimpulkan bahwa variabel independen yang berupa konflik dan stres kerja dalam 
penelitian ini secara bersama-sama berpengaruh terhadap variabel dependen yaitu kinerja tenaga kesehatan.

Tabel 10

Hasil Perhitungan

\begin{tabular}{lccccl}
\hline \multicolumn{1}{c}{ Variabel } & Nilai & Sig.t & Df & t hitung & Keterangan \\
\hline Konflik & 0,284 & 0,000 & 83 & 4,521 & Signifikan \\
\hline Stres Kerja & 0,323 & 0,000 & 85 & 5,101 & Signifikan \\
\hline
\end{tabular}

Berdasarkan hasil perhitungan yang ditujukan pada tabel 10 dapat diinterpretasikan sebagai berikut:

1. Berdasarkan hasil uji t tersebut, didapatkan hasil estimasi variabel Konflik memiliki koefisien regresi sebesar 0,284 dengan signifikansi sebesar 0,000. Pada penelitian ini, nilai koefisien positif $(+)$ pada variabel Konflik memiliki arah negatif terhadap variabel Kinerja Tenaga Kesehatan karena pernyataan dalam kuesioner pada variabel Konflik merupakan pernyataan negatif (unfavorable). Nilai thitung $(4,521)>\mathrm{t}$ tabel $(2,000)$, maka dapat disimpulkan bahwa $\mathrm{H}_{0}$ ditolak yaitu ada pengaruh negatif dan signifikan antara Konflik terhadap Kinerja Tenaga Kesehatan.

2. Berdasarkan hasil uji t tersebut, didapatkan hasil variabel Stres Kerja memiliki koefisien regresi sebesar 0,323 dengan signifikansi sebesar 0,000. Pada penelitian ini, nilai koefisien yang positif $(+)$ pada variabel Stres Kerja memiliki arah negatif terhadap variabel Kinerja Tenaga Kesehatan karena pernyataan dalam kuesioner pada variabel Stres Kerja merupakan pernyataan negatif (unfavorable). Nilai t hitung $(5,101)>\mathrm{t}$ tabel $(2,000)$, maka dapat disimpulkan bahwa $\mathrm{H}_{0}$ ditolak yaitu ada pengaruh negatif dan signifikan antara Stres Kerja terhadap Kinerja Tenaga Kesehatan.

3. Berdasarkan hasil uji t tersebut, didapatkan hasil variabel Konflik dan Stres Kerja memiliki koefisien regresi sebesar 0,284 dan 0,323 dengan signifikansi sebesar 0,000. Pada penelitian ini, nilai koefisien yang positif $(+)$ pada variabel Konflik dan Stres Kerja memiliki arah negatif terhadap variabel Kinerja Tenaga Kesehatan karena pernyataan kuesioner pada variabel konflik dan Stres Kerja merupakan pernyataan negatif (unfavorable). Nilai signifikansi atau $p$-value $<\alpha$ $(0,05)$ menunjukkan bahwa variabel Konflik dan Stres Kerja signifikan berpengaruh terhadap Kinerja Tenaga Kesehatan. Nilai t hitung (4,521 dan $5,101)>\mathrm{t}$ tabel $(2,000)$, maka dapat disimpulkan bahwa $\mathrm{H}_{0}$ ditolak yaitu ada pengaruh negatif dan signifikan antara Konflik dan Stres Keja terhadap Kinerja Tenaga Kesehatan.

\section{Diskusi Penelitian}

\section{Konflik Mempengaruhi Kinerja Tenaga Kesehatan di RSUD Wangaya Denpasar}

Konflik selalu muncul dalam organisasi dan tidak dapat dihindari saat dalam bekerja. Berdasarkan hasil penelitian yang sudah dilakukan yaitu didapatkan hasil bahwa konflik berpengaruh negatif dan signifikan terhadap kinerja tenaga 
kesehatan. Hasil yang didapatkan bahwa konflik yang terjadi dengan tingkat rendah ke sedang dengan kinerja sedang ke tinggi.

Pengaruh konflik terhadap kinerja tenaga kesehatan di RSUD Wangaya Denpasar pada gambar 6.1 didapatkan dari hasil penelitian yang menunjukkan bahwa angka konflik sebesar 37,5\% didapatkan dari nilai median (nilai tengah) dari tingkat konflik rendah (0\%) sampai tingkat konflik sedang (75\%), sedangkan angka kinerja tenaga kesehatan sebesar $77,5 \%$ didapatkan dari nilai median dari tingkat kinerja sedang minimal (55\%) sampai tingkat kinerja tinggi maksimal (100\%) dan dilihat dari grafik tersebut dalam keadaan menanjak. artinya semakin rendah terjadinya konflik maka semakin tinggi kinerja tenaga kesehatan. Menurut Marwansyah (2019) mengatakan bahwa konflik rendah dapat meningkatkan kerjasama tim, dapat meningkatkan kualitas diri tenaga kesehatan sehingga kinerja tenaga kesehatan semakin tinggi. Hasil penelitian menunjukkan bahwa konflik yang terjadi adalah sebagian besar dengan tingkat konflik sedang yaitu sebesar $74,4 \%$. Pernyataan yang paling berpengaruh terhadap terjadi konflik adalah pernyataan "Saya merasakan antara saya dengan rekan kerja mempunyai perbedaan dalam menentukan cara penyelesaian pekerjaan".

Hasil penelitian ini sejalan dengan Retnaningrum dan Musadieq (2016) yang berjudul Pengaruh "Work-Family Conflict terhadap Kepuasan Kerja dan Kinerja (Studi pada Perawat Wanita RSUD Wonosari Yogyakarta)" menyatakan bahwa konflik berpengaruh negatif signifikan terhadap kinerja pegawai. Sama halnya dengan penelitian Kim, Ji, dan Shin (2019) yang berjudul "The Effects of Role Conflict and Role Ambiguity on Team Performance and the Mediating Effects of Relationship Conflict and Task Conflict among Hospital Employees" yang mengatakan bahwa Konflik berpengaruh negatif signifikan terhadap kinerja tenaga kesehatan.

\section{Stres Kerja Mempengaruhi Kinerja Tenaga Kesehatan di RSUD Wangaya Denpasar}

Salah satu usaha untuk meningkatkan kinerja adalah dengan memperhatikan stres kerja (Arfani \& Luturlean, 2018). Berdasarkan hasil penelitian yang sudah dilakukan yaitu didapatkan hasil stres kerja berpengaruh negatif dan signifikan terhadap kinerja tenaga kesehatan. Pengaruh stres kerja terhadap kinerja tenaga kesehatan di RSUD Wangaya Denpasar pada gambar 6.2 yang didapatkan dari hasil penelitian menunjukkan bahwa stres kerja dalam tingkat rendah ke sedang dengan kinerja sedang ke tinggi. Angka stres kerja sebesar 37,5\% didapatkan dari nilai median (nilai tengah) dari tingkat stres kerja rendah (0\%) sampai tingkat konflik sedang (75\%), sedangkan angka kinerja tenaga kesehatan sebesar 77,5\% didapatkan dari nilai median dari tingkat kinerja sedang minimal (55\%) sampai tingkat kinerja tinggi maksimal (100\%). Maka dapat dilihat grafik dalam keadaan menanjak artinya stres kerja rendah dapat menghasilkan kinerja yang tinggi. Menurut Wahyudi (2017), stres kerja yang rendah dapat membuat tenaga kesehatan menjadi lebih berprestasi dan mencapai tujuan yang ditargetkan sehingga berdampak pada kinerja yang tinggi. Hasil penelitian menunjukkan bahwa stres kerja yang terjadi adalah sebagian besar dengan tingkat stres kerja sedang yaitu sebesar 91,9\%. Pernyataan yang paling berpengaruh terhadap terjadi stres kerja adalah pernyataan "Pekerjaan saya berisiko tinggi". 
Bali Medika Jurnal.

Vol 8 No 1, 2021: 13-26

ISSN : 2615-7047

DOI: https://doi.org/10.36376/bmj.v8i1

Hasil penelitian ini sejalan dengan Santas, Isik, dan Demir (2016) dengan judul penelitian "The Effect of Loneliness at Work, Work Stress on work Alienation and Work Alienation on Employees'Performance in Turkish Health Care Institution" menyatakan bahwa stres kerja berpengaruh negatif terhadap kinerja dan juga didukung oleh penelitian Nurcahyani, Widodo, dan Rosdiana (2016) dalam judul "Hubungan Tingkat Stres Kerja dengan Kinerja Perawat di Ruang Rawat Inap Rumah Sakit Panti Waluya Sawahan Malang" menyatakan bahwa semakin rendah stres kerja pegawai maka kinerja semakin meningkat. Begitu pula dengan hasil penelitian Li et al. (2017) yang berjudul "Moderating Effects of Coping on Work Stress and Job Performance For Nurses in Tertiary Hospitals: A Cross-Sectional Survey in China" yang mengatakan bahwa stres kerja berpengaruh negatif terhadap kinerja.

\section{Konflik dan Stres Kerja Mempengaruhi Kinerja Tenaga Kesehatan di RSUD Wangaya Denpasar}

Setiap tenaga kesehatan dituntut untuk memiliki kinerja yang baik sesuai jabatan/profesinya dan beradaptasi dengan rekan kerja yang memiliki karakter berbeda-beda. Interaksi antar individu memicu terjadinya konflik dan tugas yang berat diberikan dapat membuat tenaga kesehatan mengalami stres kerja (Anatan \& Elitan, 2012). Berdasarkan hasil penelitian didapatkan hasil konflik dan stres kerja bersama-sama mempengaruhi kinerja tenaga kesehatan. Konflik dan Stres Kerja berpengaruh negatif dan signifikan terhadap kinerja tenaga kesehatan di RSUD Wangaya Denpasar, yang artinya semakin rendah konflik dan stres kerja maka semakin tinggi kinerja tenaga kesehatan. Konflik dan stres kerja yang rendah dapat menimbulkan dampak positif, yaitu misalnya dapat berkembangnya kedisiplinan dan ketertiban dalam menggunakan waktu bekerja, hubungan kerjasama yang meningkat sehingga produktif, motivasi kerja meningkat dan kinerja menajdi semakin tinggi (Wijono, 2012).

Hasil penelitian menunjukkan bahwa kinerja tenaga kesehatan adalah sebagian besar dengan tingkat kinerja sedang yaitu sebesar 55,8\%. Pernyataan yang paling berpengaruh terhadap terjadi kinerja adalah pernyataan "Saya bisa mencapai standar hasil kerja rumah sakit "Kinerja tenaga kesehatan dapat dijelaskan sebesar 47,5\% oleh variabel independen yaitu konflik dan stres kerja, sedangkan 52,5\% dijelaskan variabel lain di luar variabel independen penelitian ini, dengan t hitung $(4,521$ dan 5,101) $>$ t tabel $(2,000)$.

Hasil penelitian ini sejalan dengan Suasnawa dan Saputra (2018) dalam penelitian yang berjudul "Pengaruh Konflik Interaktif dan Stres Kerja terhadap Kinerja Karyawan di Rumah Sakit Umum Daerah X" menyatakan bahwa konflik dan stres kerja berpengaruh negatif signifikan terhadap kinerja. Menurut Sarafis et al. (2016) dalam penelitiannya yang berjudul "The Impact Of Occupational Stress on Nurses' Caring Behaviors and Their Health Related Quality of Life" menyatakan bahwa konflik dan stres kerja berpengaruh negatif dan signifikan terhadap kinerja.

Agar konflik yang terjadi dapat berdampak positif dan fungsional terhadap kinerja tenaga kesehatan maka pihak manajemen SDM (Sumber Daya Manusia) atau HRD (Human Resource Departement) perlu melakukan program manajemen konflik atau program pengelolaan konflik yaitu dengan cara memperluas sumber 
daya, menetapkan peraturan, mengadakan musyawarah, mengadakan negosiasi, membutuhkan pihak ketiga, mendorong adanya persaingan dengan penawaran insentif, mengevaluasi kinerja secara terpadu, memotivasi tenaga kesehatan, menetapkan standar kinerja, mengadakan kegiatan bersama, mutasi jabatan, memilih pimpinan yang demokratis, membagikan tugas baru, memberikan penghargaan atas kinerja tenaga kesehatan (Wahyudi, 2017).

Terkait dengan stres kerja, pihak manajemen SDM (Sumber Daya Manusia) atau HRD (Human Resource Departement) dapat mengelola program pengendalian stres kerja yang dirasakan oleh tenaga kesehatan dengan cara memindahkan (transfer) ke pekerjaan lain, menyediakan lingkungan kerja yang baru, mengadakan pelatihan dan pengembangan, merancang kembali tugas dan wewenang yang dikerjakan oleh tenaga kesehatan, mengadakan program olahraga rutin, mengadakan program rekreasi dan program spiritual, mengadakan cek kesehatan rutin, mengadakan program konseling, pembimbingan dan penyuluhan terkait dengan stres kerja bagi tenaga kesehatan (Handoko, 2017).

Untuk tenaga kesehatan dapat membuat konflik berdampak positif dengan melakukan komunikasi yang baik saat bekerja, memperbaiki dan menjaga hubungan baik, saling menghormati dan meningkatkan kerja sama tim (Handoko, 2017). Selain konflik, stres kerja yang dirasakan tenaga kesehatan dapat dikelola oleh tenaga kesehatan agar kinerja menjadi meningkat yaitu dengan cara mengetahui akar stres kerja, tidak terlalu serius dalam bekerja, melakukan olahraga rutin, membicarakan masalah dengan orang lain, mengerjakan tugas yang mudah, percaya diri, membuat hidup lebih teratur, mengelola waktu dengan efektif, meningkatkan produktivitas dengan cara mengerjakan tugas sesuai dengan SOP (Standar Operasional Prosedur), melakukan pelatihan, dan menciptakan rasa humor yang positif (Wahyudi, 2017).

\section{SIMPULAN DAN SARAN}

\section{Simpulan}

Konflik berpengaruh negatif dan signifikan terhadap kinerja tenaga kesehatan di RSUD Wangaya Denpasar yang artinya semakin rendah terjadi konflik maka semakin tinggi kinerja tenaga kesehatan dengan tingkat konflik yang dialami sebagian besar dengan tingkat sedang sebesar 74,4\%;. Stres kerja berpengaruh negatif dan signifikan terhadap kinerja tenaga kesehatan di RSUD Wangaya Denpasar yang artinya semakin rendah stres kerja maka semakin tinggi kinerja tenaga kesehatan dengan tingkat stres kerja yang dialami sebagian besar dengan tingkat sedang sebesar 91,9\%; Konflik dan stres kerja berpengaruh negatif dan signifikan terhadap kinerja tenaga kesehatan di RSUD Wangaya Denpasar yang artinya semakin rendah konflik dan stres kerja maka semakin tinggi kinerja tenaga kesehatan dengan tingkat kinerja tenaga kesehatan yang dialami sebagian besar dengan tingkat sedang sebesar 55,8\%. Kinerja tenaga kesehatan dapat dijelaskan sebesar 47,5\% oleh variabel independen yaitu konflik dan stres kerja.

\section{Saran}

1. Kepada Manajemen Sumber Daya Manusia (SDM) dan tenaga kesehatan di RSUD Wangaya Denpasar 
Disarankan kepada Manajemen SDM di RSUD Wangaya Denpasar untuk memaksimalkan program pengelolaan konflik dan stres kerja yang sudah ada, seperti rapat dan mutasi jabatan. Jika konflik terjadi diharapkan dapat diselesaikan secara cepat dan dapat diupayakan untuk solusi yang efektif. Begitu juga dengan stres kerja, diharapkan pengelolaan stres kerja yang sudah ada seperti olahraga rutin lebih dimaksimalkan untuk kehadiran tenaga kesehatan. Kepada tenaga kesehatan disarankan untuk lebih peka terhadap konflik yang terjadi dan dapat melaporkan ke pihak manajemen SDM jika ada konflik sehingga konflik lebih cepat teratasi. Begitu pula dengan stres kerja, diharapkan tiap tenaga kesehatan dapat melakukan olahraga rutin agar stres kerja dapat terkelola dengan baik.

2. Kepada peneliti selanjutnya

Kepada peneliti selanjutnya agar lebih mengembangkan penelitian yang berkaitan dengan konflik dan stres kerja terhadap kinerja tenaga kesehatan dengan ruang lingkup yang lebih luas dan jumlah sampel yang lebih besar, serta meneliti lebih jauh mengenai faktor-faktor lain seperti motivasi kerja, disiplin kerja dan stres kerja terhadap kinerja tenaga kesehatan serta konflik dan stres kerja terhadap kepribadian tenaga kesehatan.

\section{UCAPAN TERIMA KASIH}

Peneliti banyak mendapat bantuan sejak awal hingga terselesainya penelitian ini, untuk itu dengan segala hormat dan kerendahan hati, peneliti menyampaikan terima kasih yang sebesar - besarnya kepada Rektor Universitas Bali Internasional, Dekan Fakultas Ilmu-Ilmu Kesehatan dan Ketua Program Studi Administrasi Rumah Sakit, Direktur dan seluruh staf RSUD Wangaya Denpasar yang memfasilitasi dan memberikan ijin untuk melakukan penelitian di RSUD Wangaya Denpasar, serta seluruh responden yang telah terlibat dalam penelitian ini.

\section{DAFTAR PUSTAKA}

Anatan, L., \& Elitan, L. (2012). Manajemen Sumber Daya Manusia dalam Bisnis Modern. Bandung: Alfabeta.

Andri, G. (2016). Analisis Stres Kerja dan Konflik Kerja terhadap Kinerja Pegawai Instalasi Bedah Sentral (IBS) RSUP Dr. Cipto Mangunkusumo Jakarta. Jurnal Bisnis Dan Manajemen, 4(1), 61-71.

Arfani, M. R., \& Luturlean, B. S. (2018). Pengaruh Stres Kerja dan Beban Kerja terhadap Kinerja Karyawan Di PT Sucofindo Cabang Bandung. EProceeding Of Management, 5(2), 2770.

Cui, X., Dunning, D. G., \& An, N. (2017). Satisfaction Among Early And MidCareer Dentists In A Metropolitan Dental Hospital In China. Journal of Health Care and Leadership. https://doi.org/10.2147/JHL.S137071

Find Employment England. (2014). Survey: Majority of Employees Experience Conflict at Work. Retrieved from clomedia.com website: http://www.clomedia.com/2014/02/05/survey-majority-of-employeesexperience conflict-at-work/

Handoko, T. A. (2017). Manajemen Personalia dan Sumber Daya Manusia. 
Yogyakarta: BPFE.

Health and Safety Executive. (2018). Work Related Stress Depression or Anxiety Statistics in Great Britain. Retrieved from hse.gov.uk website:

http://www.hse.gov.uk/statistics/ causdis/stress/index.htm

Januar, D. (2018). Pengaruh Konflik Peran dan Keputusan Etis melalui Stress

Kerja terhadap Prestasi Kerja Pegawai Wanita Rumah Sakit Daerah Kalisat

Kabupaten Jember. Jurnal Bisnis Dan Manajemen, 12(1), 20-27.

Khamisa, N., Peltzer, K., Ilic, D., \& Oldenburg, B. (2017). Effect of Personal and

Work Stress on Burnout, Job Satisfaction and General Health of Hospital

Nurses in South Africa. Health Sa Geson Dheid, 22, 252-258.

Kim, T. K., Ji, J. H., \& Shin, H. K. (2019). The Effects of Role Conflict and Role Ambiguity on Team Performance and the Mediating Effects of Relationship Conflict and Task Conflict among Hospital Employees. Journal of Health Informatics and Statistics, 44(2), 172-180.

Li, L., Hua, A., Lei, G., Hao, Z., Xinyan, L., Zhong, Z., ... Lihua, F. (2017).

Moderating Effects of Coping on Work Stress and Job Performance For Nurses in Tertiary Hospitals: A Cross-Sectional Survey in China. BMC Health Services Research, 17.

Marwansyah. (2019). Manajemen Sumber Daya Manusia. Bandung: Alfabeta. Nurcahyani, E., Widodo, D., \& Rosdiana, Y. (2016). Hubungan Tingkat Stres Kerja dengan Kinerja Perawat di Ruang Rawat Inap Rumah Sakit Panti Waluya Sawahan Malang. Nursing News, 1(1).

Pratika, N. D. (2017). Pengaruh Konflik Interpersonal dan Beban Kerja terhadap Stres Kerja serta Implikasinya pada Kinerja Perawat di Ruang Rawat Inap Rumah Sakit Ramahadi Kab.Purwakarta. Universitas Pasundan.

Putra, P. S. P., \& Susilawati, L. K. P. A. (2018). Hubungan antara Dukungan Sosial dan Self Efficacy dengan Tingkat Stres pada Perawat di Rumah Sakit Umum Pusat Sanglah. Jurnal Psikologi Udayana, 5(1), 145-157.

Retnaningrum, A. K., \& Musadieq, M. A. (2016). Pengaruh Work-Family Conflict terhadap Kepuasan Kerja dan Kinerja (Studi pada Perawat Wanita RSUD Wonosari Yogyakarta). Jurnal Administrasi Bisnis, 36.

Santas, G., Isik, O., \& Demir, A. (2016). The Effect of Loneliness at Work, Work Stress on Work Alienation and Work Alienation on Employees'Performance in Turkish Health Care Institution. Outh Asian Journal of Management Sciences, 10(2), 30-38.

Sarafis, P., Rousaki, E., Tsounis, A., Malliarou, M., Lahana, L., Bamidis, P., ... Papastavrou, E. (2016). The Impact of Occupational Stress on Nurses' Caring Behaviors and Their Health Related Quality of Life. BMC Nursing, 15(56).

Setiawan, L. (2017). Pengaruh Emotional Intellegence, Knowledge Sharing dan Team Conflict terhadap Team Performance di Rumah Sakit Undata Palu. Jurnal Riset Edisi XVII, 3(6).

Sinambela, L. P. (2017). Manajemen Sumber Daya Manusia. Jakarta: Bumi Aksara.

Suasnawa, I. G., \& Saputra, I. G. N. M. Y. (2018). Pengaruh Konflik Interaktif dan Stres Kerja terhadap Kinerja Karyawan di Rumah Sakit Umum Daerah "X." Bali Health Journal, 2(1). 
Wahlberg, A., Sachs, M. A., Johannesson, K., Hallberg, G., Jonsson, M., Svanberg, A. S., \& Horgberg, U. (2016). Post-Traumatic Stress Symptoms In Swedish Obstetricians And Midwives After Severe Obstetric Events: A Cross-Sectional Retrospective Survey. BJOG Journal, 1264-1227. https://doi.org/10.1111/1471-0528.14259

Wahyudi. (2017). Manajemen Konflik dan Stres dalam Organisasi Pedoman Praktis bagi Pemimpin Visioner. Bandung: Alfabeta.

Waluyo, M. (2013). Psikologi Industri. Jakarta: Akademia Permata.

Wijono, D. (2012). Manajemen Mutu Pelayanan Kesehatan: Teori, Strategi dan Aplikasi (2nd ed.). Surabaya: Airlangga University Press.

World Health Organization. (2015). Plan of Action Workers' Health 2015-2025. Retrieved from iris.paho.org website: http://iris.paho.org

Yana, D. (2014). Stres Kerja Pada Perawat Instalasi Gawat Darurat Di RSUD Pasar Rebo Tahun 2014. Jurnal Administrasi Rumah Sakit Indonesia, 1(2). 